\title{
La "figura" en los Pensées. Origen, significados e interpretación
}

\author{
Alberto MIRA ALMODÓVAR
}

\begin{abstract}
RESUMEN
¿Cómo se puede explicar que una palabra - figurapueda penetrar, a través de su desarrollo significativo, en una situación histórica, y cómo pueden derivarse de tal situación estructuras (religiosas y literarias) que mantienen su vigencia durante siglos? Blaise Pascal, en sus Pensées, recogiendo la tradición pagana y cristiana del desarrollo significativo de figura elabora su radical y singular metodología exegética bíblica.
\end{abstract}

PALABRAS CLAVE: Figura, Consumación, Interpretación figural, Profecía real, Imaginación, Verdad

\begin{abstract}
How can you explain that a word -'figura'- can pervade, through its significant development, in a historical situation, and how they can arise from such a situation structures (religious and literary) that remain into effect for centuries? Blaise Pascal, in his Pensées, collecting Pagan and Christian tradition of significant development of 'figura' elaborates his radical and unique biblical exegetic methodology.
\end{abstract}

KEYWORDS:Figure, Consummation, Figural interpretation, Real prophecy, Imagination, Truth

«Un même sens change selon les paroles qui l'expriment. Les sens reçoivent des paroles leur dignité au lieu de la leur donnen»

Blaise Pascal, Pensées (L 789, B 50)

Puesto que el proyecto de Jean Mesnard de llevar a cabo la definitiva edición crítica de las obras de Blaise Pascal en siete volúmenes, iniciada en el año 1967 y conocida como la del "tricentenario", aún no ha culminado -y no sabemos si se completará-, quedando pendiente, entre otros escritos, la edición de los Pensées ${ }^{1}$, para su lectura deberemos seguir utilizando como base las dos ediciones académicamente más serias de esta obra, es decir, la de León Brunschvicg, de 1897, y la de Louis Lafuma, de 1951. Brunschvicg se atiene al criterio temático, agrupando los fragmentos en bloques de significados próximos, de manera que el texto adquiere una continuidad en su exposición. Por el contrario, Lafuma recoge los fragmentos pascalianos en el orden en el que se encuentran situados en los diversos legajos que los parientes y amigos de Pascal encontraron tras su muerte en el año 1662, como notas destinadas, en su mayor parte, a la composición de una apología

\footnotetext{
${ }^{1}$ Contamos con una excelente edición digital de los Pensées, a cargo de D. Descotes y G. Proust, en la que, entre otras, podemos hallar la correlación de los fragmentos pascalianos en las ediciones de Brunschvicg y Lafuma: http://www.penseesdepascal.fr
} 
de la religión cristiana. Ambas son de gran utilidad para la lectura de estas notas pascalianas, por lo cual para las citas de los Pensées seguiremos utilizando ambas referencias correlacionadas, con la signatura Lxxx, Byyy. Pues bien, al adentrarnos en la lectura de estas notas, siguiendo la edición Lafuma, nos encontramos con el legajo XIX, cuyos treinta y un fragmentos requieren la máxima atención del lector no experto en materia de exégesis bíblica por la dificultad añadida en su interpretación. La mayoría de estos treinta y un fragmentos se localizan en la sección $\mathrm{X}$ de la edición de Brunschvicg. Mas en esta misma sección X y en las secciones XI, XII y XIV, Brunschvicg incluye otros treinta fragmentos más de otros legajos agrupados bajo la misma temática que los del legajo XIX de la edición Lafuma.

En estos fragmentos las notas de Pascal están dedicadas en su mayor parte a situar el problema de la verdad histórica de la religión cristiana mediante la hermenéutica de los textos del Antiguo Testamento (en adelante, AT) y su relación de continuidad anunciada y cumplida en el Nuevo Testamento ${ }^{2}$ (en adelante, NT), siendo la palabra figura la que transita de forma más notoria -explícita e implícita- por ellos. Pascal pretende dar a entender de qué forma Dios se da a conocer por medio de signos, profecías o pruebas de hecho que se muestran en el AT de modo figurado, y de qué manera lo manifestado en el NT contiene las claves que descifran eso figurado en el AT. Agustín de Tagaste resume la interrelación de ambos libros indicando que «en el Antiguo Testamento está oculto el Nuevo, y en el Nuevo está manifiesto el Antiguo»³ ${ }^{3}$ ya que, necesariamente, la identidad cristiana reposa en la unidad de los dos Testamentos. Mas esta unidad también pone de manifiesto la contraposición entre la "ley" (= de la Torâ), como vínculo del pueblo judío con la voluntad de Dios en la espera del Mesías, y la "ley evangélica" (= de la fe por la gracia) universal ${ }^{4}$ de la gloria, como esencia de la doctrina cristiana ${ }^{5}$. De esta manera,

\footnotetext{
2 «Llamamos «Nuevo Testamento» al pequeño libro que constituye el fundamento de la fe cristiana. Por otra parte, este libro hace constante referencia a otro que denominamos sencillamente «la Escritura» o «las Escrituras», o también «la Biblia». A este libro, crecido junto con la historia del pueblo judío hasta Cristo, los cristianos lo llamamos «Antiguo Testamento». El conjunto de las Escrituras en las que se apoya la fe cristiana, aparecen así como un «testamento» de Dios a los hombres estructurado en forma de dos escalones sucesivos, como proclamación de su voluntad al mundo». Joseph Ratzinger, La Iglesia, Israel y las demás religiones, Madrid, Ciudad Nueva, 2007, 41, trad. Pablo García Macho.

3 «in Vétere Novum láteat et in Novo Vetus páteat». "Cuestiones sobre el Heptateuco" 2, 73, en Obras completas de san Agustin, XXVIII, Escritos bíblicos (4), Madrid, BAC 504, 1989, 230.

${ }^{4}$ L 301, B 772; Joel 3, 1; Hechos 2, 16-21.

5 «En el lugar de la ley se introduce la gracia. El redescubrimiento de la teología paulina en la Iglesia de la Reforma pone el acento precisamente en este aspecto: no las obras, sino la fe; no lo que hace el hombre,
} 
Cristo, como el Mesías, establece la unión en la continuidad de los mensajes y, al mismo tiempo, la separación entre la ley de Israel y la ley de la Iglesia. Pero, ¿por qué la utilización de la palabra figura en la apología cristiana, a la cual destinara sus notas Blaise Pascal, como para concederle un lugar determinante frente a otras formas de representación (v. gr., tropos y/o símbolos) que pudieran dar razón -para el cristianodel antagonismo y, a la vez, continuidad necesaria entre lo contenido en el AT y lo indicado en el NT? Para dar respuesta a esta pregunta contamos con un indispensable ensayo, de 1967, del filólogo berlinés de origen judío Erich Auerbach, de preciso y ajustado título para el interés de nuestro análisis: Figura ${ }^{6}$, en el que se ofrece una clara exposición metodológica mediante la cual asistir al origen y significados de la palabra figura en la Antigüedad pagana y al singular desarrollo posterior de la interpretación figural por los Padres de la Iglesia, de la que es deudora la doctrina cristológica y la dogmática cristiana.

La pretensión del estudio filológico de Erich Auerbach sobre el término figura y la interpretación figural o "el modo de concebir figuralmente el acontecer histórico", tal como indica el propio autor, es la de mostrar cómo una palabra (figura) puede penetrar, a través de su desarrollo significativo, en una situación histórica, y cómo pueden derivarse de tal situación estructuras que mantienen su vigencia durante siglos. La situación histórica que movió a Pablo de Tarso a la evangelización de los paganos dio lugar a la interpretación figural; siendo este modo de interpretación -vigente en la dogmática cristiana ${ }^{7}$ - determinante en la expansión de la nueva doctrina por su influencia en la

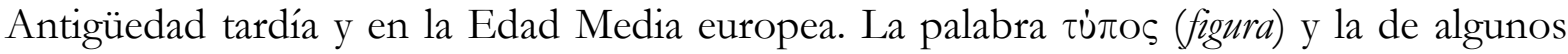

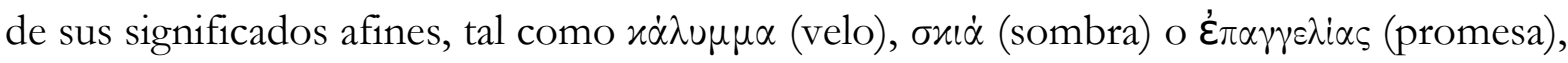
como indica Cuesta Abad en el prólogo a Figura, actuaron como núcleo de la "hermenéutica histórica" del cristianismo, cuya doctrina de la interpretación figural

sino la libre disposición de la bondad de Dios. De ahí que haya subrayado también con fuerza que no se trata de «alianza» sino de «testamento», de una pura disposición de Dios». Joseph Ratzinger, La Iglesia, Israel y las demás religiones, 60.

${ }^{6}$ Erich Auerbach, Figura, Madrid, Mínima Trotta, 1998, prólogo: J. M. Cuesta Abad, trad. Y. García Hernández [original: Figura. Sacrae Scripturae Sermo Humilis, A. Francke AG Verlag, Bern, 1967].

${ }^{7}$ Como ejemplo de interpretación figural vigente ver la Constitución pastoral Lumen gentium, 21/11/1964, I, 2 y 6; II, 9; IV, 35. Edición digital: http://www.vatican.va/archive/hist councils/ ii_vatican_council/documents/vat-ii_const 19641121_lumen-gentium_sp.html. También ver la Encíclica Gaudium et spes, 7/12/1965, Parte 1ª, I, 22; III, 39; Parte 2a , V, 78. Edición digital: http:// www.vatican.va/archive/hist_councils/ii_vatican_council/documents/vat-ii_const 19651207 gaudiumet-spes sp.html 
implicaba, de una parte, la necesidad de una correlación entre los textos del AT y del NT, y, de otra, la anexión del AT al NT en el modo de una relación de contrapunto de acontecimientos que unificara el desarrollo de la historia sagrada mediante un esquema totalizador e universal. El ensayo del filólogo berlinés sobre el método o interpretación figural tiene como principal intención -no lo olvidemos- la de exponer un problema hermenéutico que afecta esencialmente a la comprensión de la tradición literaria europea, ya que la historia y la crítica literarias recurren, por lo común, a los conceptos de símbolo y alegoría como categorías hermenéuticas autorizadas desde la literatura clásica antigua hasta la cristiano-medieval, descuidando -y la mayoría de veces ignorando- la importancia durante siglos de la interpretación figural; y, a su vez, al no pretender su autor establecer discusiones a resolver en el marco teológico, este trabajo despeja un camino sin atajos que conduce a un análisis filológico clave acerca de la utilización del término figura y de la interpretación figural por los Padres de la Iglesia. Y es precisamente el recorrido por la estructura y el desarrollo establecido por Auerbach en Figura -en lo que a nuestro objeto de estudio interesa- lo que nos abre las puertas del edificio conceptual que Pascal construye en los fragmentos de los Pensées dedicados al uso, significados e interpretación de la palabra figura.

\section{El origen de la palabra latina figura en la antigüedad pagana a través de sus referentes en el idioma griego}

Auerbach comienza su exposición indicando que la palabra latina figura significa originalmente "imagen plástica", documentándose por vez primera en Publio TERENCIO "El Africano" (Cartago, 194-159 a.C., según Suetonio), que en su obra Eunuchus, Acto II, 3178, fechada en 161 a.C., dice de una joven: «nova figura oris». En la misma época, Marco PACuVIO, (Brindisi, 220-130 a.C.), autor trágico, que compuso 12 tragedias y 365 fragmentos de poemas, incluye la expresión: «nova figura factam» en el fragmento 270/I. El hecho de que aparezca la expresión «nova figura» en las dos citas documentadas más antiguas muestra el carácter peculiar de la palabra figura como la expresión de "lo que se manifiesta de nuevo" y, a su vez, de "lo que se transforma". A partir de esta época, la historia del desarrollo de la palabra figura se muestra con la adición de la influencia de la

\footnotetext{
${ }^{8}$ Edición digital: http://www.thelatinlibrary.com/ter.eunuchus.html
} 
predominante cultura griega sobre la educación romana, en cuya helenización -que puede situarse en el siglo I a.C.- participaron decisivamente tres notables escritores latinos: Varrón, Lucrecio y Cicerón.

En la obra de Marco Terencio VARRÓN (Rieti, 116-27 a.C.), la palabra figura adquiere el significado de "configuración externa" (forma), e incluso "contorno", aunque la novedad de Varrón para la evolución del término figura se explicita en el área de la gramática como "estructura gramatical". En su obra De lingua latina-que consta de 25 libros, de los que se conservan 6-, en el libro 9, 52, denomina la forma del plural como «figura multitudinis». A partir de Varrón, aunque la palabra "forma" fue empleada frecuentemente, los gramáticos latinos prefirieron usar mucho más a menudo el término figura.

¿Cómo fue posible que las palabras figura y “forma” pudieran adquirir rápidamente un sentido netamente abstracto, se pregunta Auerbach? El idioma griego, cuyo léxico científico-retórico era mucho más rico que el del latín, poseía un gran número de

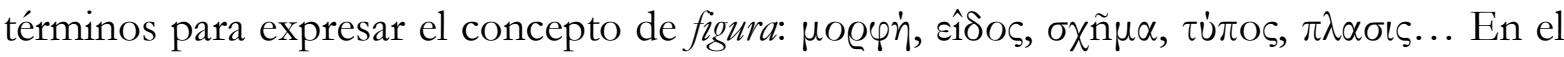
ámbito del uso platónico-aristotélico del idioma, la formación filosófica y retórica había asignado a cada una de estas palabras su campo semántico propio, trazando una clara división entre $\mu о \varrho \varphi \dot{\eta}$ y $\varepsilon \hat{i} \delta o \varsigma$, como la "forma" o la "idea" que constituyen o informan de la materia, y $\sigma \chi \tilde{n} \mu \alpha$, que expresa la "configuración puramente sensorial" de dicha "forma”. La cita clásica al respecto se encuentra en Aristóteles, Metafísica VII, 3, 1029a, 4-

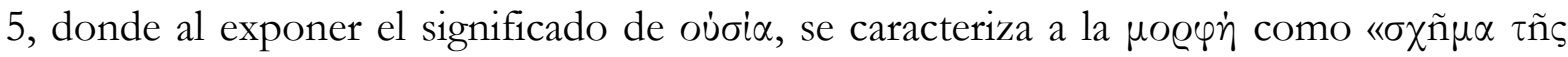

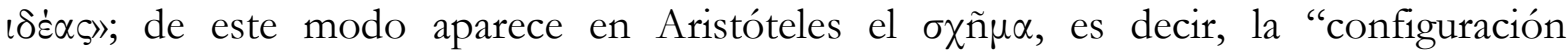
puramente sensorial" de la "forma", como una categoría de la cualidad. Se imponía de

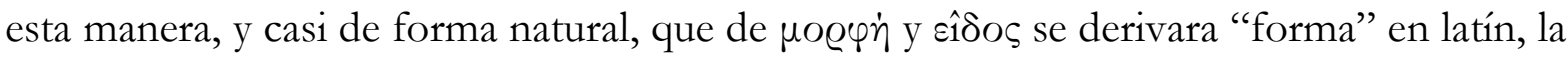
cual, originariamente, implica la idea de "modelo"; por el contrario, a $\sigma \chi \tilde{n} \mu \alpha$ le corresponde casi siempre el término figura en idioma latino. El hecho de que $\sigma \chi \tilde{n} \mu \alpha$, en el sentido de "configuración puramente sensorial o externa", se hubiera extendido ampliamente por la terminología científica griega -tanto en gramática, retórica, lógica o matemática-, explica que en latín apareciera por todas partes la palabra figura; siendo así que, junto al significado original de "imagen o forma plástica", figura aparece como concepto más genérico de "manifestación sensorial", o forma gramatical, retórica, lógica, o matemática. No se perdió totalmente el significado de "imagen plástica", puesto que 
también $\tau \dot{\pi} \pi \mathrm{o}$ se convirtió en "impresión” o “impronta”. De esta manera, a partir del significado de $\tau \dot{\pi} \pi$ os se desarrolló la palabra figura también como acepción de la "impresión de un sello", sentido metafórico que cuenta con una notable historia desde Aristóteles. La palabra griega $\tau \dot{u} \pi 0 \varsigma$ - más allá de su referencia a «imagen plástica»- ha influido decisivamente en el término figura debido a su tendencia a designar lo general, lo regulado por leyes, lo ejemplar; lo cual contribuyó a borrar la poco consistente línea que la separaba de "forma". Al unirse figura con palabras como $\pi \lambda \dot{\alpha} \sigma \iota \varsigma$ se refuerza la tendencia de la misma a expandirse hacia el sentido de "estatua", "cuadro" o "retrato". Así, si bien, en general, el término figura se corresponde en el uso lingüístico latino con la palabra griega $\sigma \chi \tilde{n} \mu \alpha$, no por ello queda agotado su potencial léxico, pues la palabra figura llega a ser más dinámica, vigorosa y dotada de mayor capacidad de difusión que el significado de la propia expresión griega $\sigma \chi \tilde{n} \mu \alpha$.

El romano Tito LUCRECIO Caro (94-51 a.C.) utiliza la palabra figura en el sentido filosófico griego, de una manera peculiar. El concepto genérico de "configuración" transita hacia "imitación" y el de "prototipo original" a "copia". Como ejemplo podemos tomar los pasajes en De rerum natura que tratan del parecido entre hijos y padres: «De ahí Venus saca a la luz figuras de suertes diversas y reproduce los rasgos de los antepasados» ${ }^{9}$, explicitando, de esta manera, cómo mediante la palabra figura se puede llevar a cabo con menos fisuras la correlación entre el "prototipo original" y la "copia", entre "forma" e “imagen".

En la obra de Marco Tulio CiCERÓN (Arpino, 106 a.C.-Formies, 43 a.C.) aparecen representadas todas las variantes del concepto general de "configuración" que le fueron sugeridas por su actividad política, retórico-literaria, jurídica y filosófica. Su principal aportación fue la de introducir y adaptar el concepto de figura como "configuración sensorial". De esta manera, los estudiantes de las escuelas de retórica, para quienes los escritos de Cicerón sobre la elocuencia oratoria constituían obras canónicas, pronto se acostumbraron a las combinaciones y fórmulas expresivas de la palabra figura.

Mas es en Publio Ovidio Nasón (Sulmona, 43 a.C.-17 d.C.) donde se encuentra la fuente más fecunda de la palabra figura en el sentido de "transformación de una

${ }^{9}$ Lucrecio, De rerum natura 4, 1223, Barcelona, Acantilado, 2012, 402-403. 
configuración”. Como ejemplo, en su Metamorfosis ${ }^{10}$ se hallan una gran variedad de usos, al igual que en Cartas de las heroinas ${ }^{11}$. En cualquier caso, en todos los pasajes de la obra de Ovidio la palabra figura sugiere algo dinámico, transformable y expuesto al equívoco.

Un nuevo y singular uso de la palabra figura se encuentra en Marco VITRUBIO Polión (75-15 a.C.). Para este gran arquitecto el término figura designa la forma plástica y arquitectónica, o su reproducción. En su principal tratado, De architectura, no se halla rastro de los conceptos de lo ilusorio, de lo equívoco o de la transformación, siendo así que figura no significa en su vocabulario nada que tenga que ver con lo efectuado por medio de la ilusión, sino algo creado por medio de un modelo semejante.

Sin embargo, el hecho más importante y de mayor trascendencia para el desarrollo de la palabra figura en la antigüedad pagana, y más en concreto en el siglo I d.C., fue la formación del concepto de «figura retórica», cuya expresión se encuentra en los libros VIII y IX de la obra Institutio oratoria ${ }^{12}$, de Marco Fabio QUINTILIANO (Calahorra, 35-95 d.C.). En estos libros se explican los medios y procedimientos de estilo: los tropos, las figuras y la composición. Al comienzo del capítulo VI del libro VIII Quintiliano define el tropo como «la mutación del significado de una palabra a otro, pero con gracia»13; y establece dos tipos de tropos: los que sirven para la significación, como la metáfora, sinécdoque, metonimia, antonomasia, onomatopeya y catacresis; y los que sirven para el adorno, como la alegoría, epiteto, enigma, ironía, perifrasis, hipérbaton e hipérbole. Asimismo, en los tres primeros capítulos del libro IX, el autor hispano-romano diferencia los tropos de las figuras $^{14}$. Mas el contraste entre ambos modos de expresión no siempre queda establecido sin vacilación en la asignación a una u otra categoría. De hecho Quintiliano especifica

\footnotetext{
${ }^{10}$ Ovidio, Metamorfosis I, 436-437: «produjo especies innumerables, reprodujo en parte las figuras antiguas y creó en parte nuevas maravillas»; VIII, 730: «hay quienes tienen la facultad de pasar a muchas figuras»; XI, 634: «despierta a un artífice y simulador de figuras, a Morfeo»; XV, 171-172: «el alma es siempre la misma, pero emigra a diferentes figuras»; XV, 253: «la naturaleza rehace unas figuras a partir de otras».

11 Ovidio, Cartas de las heroinas 14, 97: «bebes de la fuente y contemplas estupefacta tu figura».

${ }^{12}$ Edición digital en latín: http://www.intratext.com/IXT/LAT0332/ P2F.HTM

Y http://www.intratext.com/IXT/LAT0332/ P2G.HTM

En español: M. Fabio Quintiliano, Instituciones oratorias, Biblioteca Clásica, 2 tomos, Madrid, 1916. Edición digital: http://fama2.us.es/fde/ocr/2008/instituciones_Oratorias_Quintiliano_T2.pdf

${ }^{13}$ M. Fabio Quintiliano, Instituciones oratorias, tomo 2, 68.

14 «Tropo es un modo de hablar trasladado de la natural y primera significación a otra para el adorno de la oración, o, como los más de los gramáticos le definen, es una dicción trasladada de aquel lugar en que es propia a aquel en que no es propia. La figura, como por el mismo nombre se ve, es una manera de hablar apartada del modo común y más obvio. Por lo que en los tropos se ponen unas palabras por otras. Mas nada de esto acaece en las figuras. Pues la figura puede formarse en las palabras propias y por su orden colocadas». Ibidem, 83 y 84 .
} 
qué es lo que debemos entender por figura, «pues de dos modos se explica: por el primero entendemos cualquiera forma del concepto, como sucede en los cuerpos, los cuales, cualquiera que sea su composición, tienen seguramente alguna figura. El segundo, que propiamente [en el léxico griego] se llama $\sigma \chi \tilde{n} \mu \alpha \tau \alpha$ (esquema), quiere decir una mutación razonable en el sentido o en las palabras del modo vulgar y sencillo» ${ }^{15}$. De esta manera, según el primer modo, ninguna cosa hay que no sea figurada. «Pero si se ha de dar el nombre de figura a una cierta [h]orma exterior, o, por decirlo así, a una aptitud de la oración, será preciso entender en este lugar por esquema ó figura aquello que en verso o prosa se aparta del modo sencillo y obvio de decir [...] Dese, pues, por cosa sentada que figura no es otra cosa que un nuevo modo de decir con algún artificio» ${ }^{16}$. De la misma manera que con los tropos, Quintiliano clasifica las figuras en dos tipos: las que se vinculan con la expresión (figurae verborum) y las que se refieren al contenido o pensamiento (figurae sententiarum).

\section{La interpretación figural en los primeros escritos del cristianismo antiguo}

Teniendo en cuenta el proceso anteriormente señalado de las significaciones del término figura en la antigüedad pagana, ¿cómo explicar el hecho de que esta palabra adquiriera el nuevo y singular significado de profecía real en los Padres de la Iglesia como continuidad de su desarrollo histórico? Los primeros escritos de la literatura cristiana antigua -indica Auerbach - están redactados en griego, de forma que éstos conforman el cimiento de las posteriores exégesis patrísticas en léxico latino, siendo en estos escritos griegos la palabra $\tau \dot{\pi} \cos$ la que la mayoría de veces se corresponde con el concepto de profecía real. Pues bien, esta constatación es la que lleva al filólogo berlinés a la hipótesis de que figura pudo llegar a obtener su nueva significación específica partiendo de su significado general en la antigüedad pagana, es decir, el de "imagen plástica" como formación, modelado o configuración, pues así parece sugerirlo el uso lingüístico de los más antiguos escritores eclesiásticos latinos cuando se dice con frecuencia de personas o sucesos del AT que figuram Christi, o que el pueblo judío figuram nostram portat, o que la Sagrada Escritura figuram delineat futurorum, etc. Mas, al mismo tiempo, en estos escritos se introduce también la idea de la palabra griega $\sigma \chi \tilde{n} \mu \alpha$ como manifestación sensorial de la forma

\footnotetext{
${ }^{15}$ Ibidem, 84.

16 Ibidem, 84-85.
} 
material, lo que a su vez implica encubrimiento, transformación de una configuración e incluso equívoco engañoso, tal como se había puesto de manifiesto en la poesía y oratoria precristianas. La diferencia entre figura y verdad (veritas); el interpretar (exponere) y el descubrir (aperire) y revelar (revelare) las figuras; el equiparar figura con sombra (umbra), bajo cuya expresión se encubre algo distinto, futuro y tácitamente verdadero; todo ello muestra, en la nueva significación atribuida a figura -que implica propiamente una representación anticipada de algo-, la vigencia del uso retórico-metafórico anterior, con la notable diferencia de que su sentido ha pasado desde un mundo nominalista y mitológico (v. gr., Ovidio) de las escuelas retóricas a un mundo real bajo un sentido espiritual que atiende a lo supuestamente auténtico. También la contraposición que en Quintiliano se daba entre figuras de expresión (figurae verborum) y de pensamiento o contenido (figurae sententiarum) se reformula y surge ahora como la diferencia entre las figurae verborum, entre las que se encuentran las palabras proféticas (analogías, parábolas, metáforas, etc.), y las figurae rerum, que son propiamente las tomadas como profecías reales o precedentes de Cristo.

Pero volvamos con Auerbach a los primeros escritos de la literatura cristiana antigua redactados en griego, en los cuales la interpretación figural suele corresponder al concepto de profecía real. Los casos más notables los encontramos en la Epístola de Bernabé (discípulo coetáneo de Pablo de Tarso) ${ }^{17}$, en la cual se encuentran pasajes significativos que incluyen la palabra griega $\tau \dot{\pi}$ os (figura), relacionada la mayoría de veces con el concepto de profecía real18, y especialmente en las propias epístolas de Pablo de Tarso, el auténtico artífice de la expansión entre los incircuncisos ${ }^{19}$ de la nueva doctrina cristiana mediante la interpretación figural, el cual «introdujo el principio de que se podía llegar a ser cristiano incluso sin aceptar antes la ley judía» ${ }^{20}$. En estas epístolas Pablo

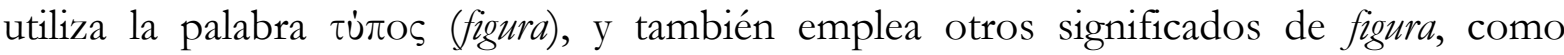

\footnotetext{
17 Gálatas 2, 1.

${ }^{18}$ Epistola de Bernabé VII, 3, 7, 10 y 11; VIII, 1; XII, 6; XIII, 5.

Edición digital en griego: http://www.ccel.org/l/lake/fathers/barnabas a.htm

Edición digital en castellano: http://escrituras.tripod.com/Textos/EpBernabe.htm

${ }^{19}$ Gálatas 2, 2-9 y Hechos 9, 15; 22, 21.

${ }^{20}$ Günter Stemberger, El judaísmo clásico. Cultura e historia del período rabinico, Madrid, Trotta, 2011, 199, trad. Lorena Miralles Maciá.
} 


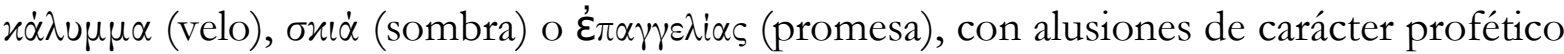
real ${ }^{21}$

Los escritos de Pablo constituyen el sustento de la nueva doctrina basada en la redención por la fe en J.C. De manera que es posible conjeturar que la interpretación figural contenida en ellos pasara a formar parte esencial de la misión evangelizadora de los primeros apologetas del cristianismo, buscando en el AT el anuncio del advenimiento de Cristo. Así, la interpretación figural paulina converge en la contraposición entre ley y gracia, entre la justificación por las obras y la fe en Cristo. La antigua ley del AT había sido abolida y reemplazada; no era más que $\sigma \varkappa i \dot{\alpha}, x \dot{\alpha} \lambda u \mu \mu \alpha$ o $\tau \dot{u} \pi \circ \varsigma$, es decir, sombra, velo o figura de lo futuro, de la nueva alianza del hombre con Dios, de la nueva doctrina contenida en el NT: el AT es la letra que mata; mientras que los seguidores de Cristo, de la nueva doctrina, son los servidores del NT, del espíritu que da vida ${ }^{22}$. Ésta era la doctrina de Pablo, el cual, como "continuador del judaísmo" buscaba en el AT las bases de apoyo para su doctrina cristológica, y, además, mediante la interpretación figural del AT, Pablo se convirtió también en "destructor de la ley judaica"23: «la culminación de la

${ }^{21}$ Epistolas de Pablo: I Corintios 10, 6 y 11, hablando de la vida de las nuevas comunidades seguidoras del mensaje de Jesús, califica a los judíos de "figuras de nosotros mismos", indicando sobre su destino que "estas cosas les sucedieron como figura"; II Corintios 3, 14, en referencia a que sólo en Cristo desaparecerá el velo con el que se lee el AT; Romanos 5, 14, Adán como figura del futuro Cristo, en referencia a la oposición entre ley y gracia; Colosenses 2, 16-17, en alusión a las cosas que son sombra de la futura realidad verdadera (Cristo); Gálatas 4, 22-23, acerca del cumplimiento de la promesa del nacimiento de los hijos de Abraham.

Edición digital en léxico original griego: http://el.wikisource.org/wiki/ $\% \mathrm{CE} \% 91 \% \mathrm{CF} \% 80 \% \mathrm{CF} \% 8 \mathrm{C} \%$ $\mathrm{CF} \% 83 \% \mathrm{CF} \% 84 \% \mathrm{CE} \% \mathrm{BF} \% \mathrm{CE} \% \mathrm{BB} \% \mathrm{CE} \% \mathrm{BF} \% \mathrm{CF} \% 82 \% \mathrm{CE} \% \mathrm{~A} 0 \% \mathrm{CE} \% \mathrm{~B} 1 \% \mathrm{CF} \% 8 \mathrm{D} \% \mathrm{CE} \% \mathrm{BB} \%$ $\mathrm{CE} \% \mathrm{BF} \% \mathrm{CF} \% 82$

22 «En realidad, ese crimen punible de muerte había sido el asesinato del protopadre, divinizado más tarde; pero la doctrina no recordó el parricidio, sino que en su lugar fantaseó su expiación, y por ello esta fantasía pudo ser saludada como un mensaje de salvación (Evangelio). Un Hijo de Dios se había dejado matar, siendo inocente, y con ello había asumido la culpa de todos». Sigmund Freud, Moisés y la religión monoteísta, Madrid, Alianza Editorial, Bolsillo, 2015, ensayo III, apartado d, 114.

Edición digital en castellano: http://www.uruguaypiensa.org.uy/imgnoticias/684.pdf, 49.

Edición digital en idioma alemán: http://ia600500.us.archive.org/21/items/DerMannMosesUndDie MonotheistischeReligion/freud moses rawpdf.pdf, 155. Ver también, 2 Corintios 3, 4-6.

${ }^{23}$ «El judaísmo había sido una religión del Padre; el cristianismo se convirtió en una religión del Hijo. El antiguo Dios-Padre pasó a segundo plano, detrás de Cristo; Cristo, el Hijo, vino a ocupar su lugar, tal como cada uno de los hijos lo había anhelado en aquellos tiempos primitivos. Pablo, el continuador del judaismo, se convirtió también en su destructor. Sin duda, su éxito obedeció, en primer lugar, al hecho de que con la idea de la redención había invocado el humano sentimiento de culpabilidad, pero además se debió a que renunció al privilegio del pueblo elegido, como lo demuestra el abandono de su signo ostentativo, la circuncisión, de manera que la nueva religión pudo alcanzar carácter universal y extenderse a todos los hombres. Aunque en este paso dado por Pablo puede haber influido su sed de venganza por la repulsa con que los judíos recibieron sus innovaciones, con él quedaba restablecido, sin embargo, un carácter de la antigua religión de Aton, su universalidad, aboliéndose así la limitación que había sufrido al pasar a su 
ley es Cristo, para (la) justificación de todo el que cree» ${ }^{24}$, pues las bases de la religión y la comunidad judías son atacadas cuando se niega la validez de la ley, de la Torá, o, mejor aún, de la halacha, esto es, del "camino" de la ley en la vida del hombre, respecto del cual todas las especulaciones teológicas son secundarias ${ }^{25}$.

\section{Desarrollo de la palabra figura en los Padres de la Iglesia}

El nuevo significado, en léxico latino, del término figura en el antiguo mundo cristiano se presenta por vez primera con Quinto Septimio Florente TERTULIANO26 (Cartago, s. IIIII), «que entre fines del siglo II e inicios del III inaugura la literatura cristiana en latín. Con él comienza una teología en ese idioma» ${ }^{27}$. En su Adversus Marcionem, escrito contra el evangelio de Marción (s. II), cuyo contenido -desaparecido- sólo se conoce por las antítesis correspondientes ${ }^{28}$, Tertuliano utiliza la palabra figura para expresar una profecía real. Así, para esta gran personalidad de la Iglesia antigua la figura tiene el sentido inmediato de una configuración o una "forma" como ese algo verdadero e histórico que representa y anuncia otro algo igualmente verdadero e histórico ${ }^{29}$. Con frecuencia, la correlación de ambos acontecimientos se muestra mediante supuestas semejanzas en la estructura del acontecimiento narrado o en sus circunstancias, de ahí que para que pueda reconocerse una figura sea precisa una determinada voluntad interpretativa para dar con ella en cada $\mathrm{caso}^{30}$. Mediante esta modalidad de interpretación figural Tertuliano muestra la identidad de personas y acontecimientos del AT en cuanto figuras o profecías reales de la historia relatada en el NT, destacando su sentido literal. De esta manera la figura

nuevo portador, el pueblo judío». Sigmund Freud, Moisés y la religión monoteísta, 116-117. En ediciones digitales: en castellano, 50; en alemán, 158.

24 Romanos 10, 4.

${ }^{25}$ Cfr. Jacob Taubes, Del culto a la cultura, Buenos Aires-Madrid, Katz Editores, 2007, 94-97. Edición digital:

http://books.google.es/books/about/Del_culto_a la cultura.html?id=pnH-6iBTd10C\&redir_esc $=y$ )

26 Para las obras de Tertuliano en latín, ver Edición digital: http://www.tertullian.org/

27 Catequesis de Benedicto XVI, 30 de mayo de 2007, dedicada a la presentación de Tertuliano. Edición digital: http://www.apologeticacatolica.org/Patristica/Patrist0707.html

${ }_{28}$ Cfr. Jacob Taubes, La teología política de Pablo, Madrid, Trotta, 2007, 69 a 76 y 141-142. Ver también Jacob Taubes, Del culto a la cultura, 182-190.

${ }_{29}$ Tertuliano, Adversus Marcionem III, 16, 3-5: «Y comenzaron a llamarlo Jesús [...] Digamos ante todo que ésta fue una prefiguración del futuro». Se trata en estos párrafos de poner nombre a Josué/Jesús, como si fuera un acto profético que anticipa sucesos posteriores.

30 Tertuliano, Adversus Marcionem V, 7, 3: «¿Por qué la Pascua es Cristo, si no por ser la Pascua figura de Cristo por semejanza con la sangre salvadora y con el cordero de Cristo?»; III, 7, en relación con el ritual del gran día de la expiación, yom ha-kippurim, relatado en Levitico 16, en el que Tertuliano interpreta dos episodios como figuras del primer y del segundo y definitivo advenimiento de Cristo. 
profética constituye un hecho concreto e histórico que se cumple y consuma en hechos igualmente concretos e históricos. Naturalmente en este proceso las figuras históricas y reales se han de interpretar al modo espiritual, dando lugar a la comprensión vinculante entre la figura y su consumación ${ }^{31}$.

En los siglos III y IV, en la obra de casi todos los escritores eclesiásticos latinos aparece ya plenamente desarrollada la palabra figura y su consiguiente interpretación figural, así como las tendencias exegéticas vinculadas a ella; pero no en todos los autores con la significación histórico-real mencionada, pues en estos primeros siglos d.C. también encontramos la interpretación figural en su modalidad puramente espiritualista alegórico-moral, como es el caso de los comentarios bíblicos de ORíGENES (Alejandría 185-254), contemporáneo de Tertuliano y Padre de la Iglesia Oriental ${ }^{32}$. La discrepancia entre ambas corrientes interpretativas introduce un nuevo conflicto en el cristianismo de los primeros tiempos. Unos autores tienden a orientar el contenido de la nueva doctrina hacia lo puramente espiritual, tratando en cierto modo de hacer desaparecer el carácter histórico del AT, mientras que otros desean conservar precisamente ese carácter histórico con sus significados. $\mathrm{Y}$ es en este escenario conflictivo entre las corrientes interpretativas representadas por Tertuliano y Orígenes en el que aparece AGUSTÍN (Tagaste-354, Hipona-430). En sus escritos ${ }^{33}$, la doctrina del cuádruple sentido de las Escrituras ${ }^{34}$ las

31 Tertuliano, Adversus Marcionem IV, 40, 3. Edición digital: http://www.tertullian.org/articles/evans marc/evans marc 09book4.htm

${ }_{32}$ Catequesis de Benedicto XVI, 25 de Abril del 2007, sobre la vida y obra de Orígenes: «La característica propia de la doctrina de Orígenes se encuentra precisamente en la incesante invitación a pasar de la letra al espíritu de las Escrituras, para progresar en el conocimiento de Dios. Y, como escribió von Balthasar, este "alegorismo", coincide precisamente "con el desarrollo del dogma cristiano realizado por la enseñanza de los doctores de la Iglesia", los cuales — de una u otra forma— acogieron la "lección" de Orígenes $[\ldots]$ El núcleo central de la inmensa obra literaria de Orígenes consiste en su "triple lectura" de la Biblia [...]: la primera es el sentido "literal", el cual encierra profundidades que no se perciben en un primer momento; la segunda dimensión es el sentido "moral": qué debemos hacer para vivir la palabra; y, por último, el sentido "espiritual", o sea, la unidad de la Escritura, que en todo su desarrollo habla de Cristo. Es el Espíritu Santo quien nos hace entender el contenido cristológico y así la unidad de la Escritura en su diversidad». Edición digital:

http://www.apologeticacatolica.org/Patristica/Patrist0706.html

33 Para las obras de Agustín en latín consultar la edición digital: http://www.augustinus.it/spagnolo/index lat.htm

${ }^{34}$ El Catecismo de la Iglesia Católica vigente, de 1992, ha recogido esta enseñanza -que proviene, al menos, desde Orígenes y su discrepancia con la corriente interpretativa de Tertuliano- y la expone en los números 115 al 119 del mismo, bajo el título "El sentido de la Escritura", y en cuyo número 115 se dice: «Según una antigua tradición, se pueden distinguir dos sentidos de la Escritura: el sentido literal y el sentido espiritual; este último se subdivide en sentido alegórico, moral y anagógico. La concordancia profunda de los cuatro sentidos asegura toda su riqueza a la lectura viva de la Escritura en la Iglesia». Para el total de la enseñanza ver edición digital: 
más de las veces adquiere un carácter concreto y fuertemente realista e histórico ${ }^{35}$, aunque Agustín intentará en su extensa obra hallar una equiparación entre ambas corrientes interpretativas.

Por el uso que hace de la palabra figura en sus escritos, Agustín recoge toda la tradición antigua, tanto pagana como cristiana, de la multiplicidad de su significado. Figura -nos indica Auerbach- aparece en la obra de Agustín para expresar el concepto general de "forma", con toda la variedad de sentidos heredados: lo estático, lo dinámico, el contorno o la formación corpórea, así como se aplica al mundo y a la naturaleza en general y a cada uno de sus objetos. También la emplea para definir lo externo y sensible, o explicar la idea de lo efímero frente a lo eterno ${ }^{36}$. En su obra, Agustín asume de manera expresa la interpretación figural del $\mathrm{AT}^{37}$ y la recomienda encarecidamente para la predicación ${ }^{38}$; oponiéndose a la mera interpretación alegórica de las Escrituras y a las exégesis que excluyeran su sentido histórico-real. Y en este aspecto se acerca más a la posición de Tertuliano que a la de Orígenes ${ }^{39}$. Así, el AT para el obispo de Hipona es pura profecía real; mostrándose acerca de esta interpretación como el más firme seguidor de los mensajes paulinos ${ }^{40}$. En cualquier caso, añade Auerbach, no hay nadie -ni entre los antecesores ni entre los coetáneos- que haya desarrollado estas ideas con tanta plenitud, perfección y profundidad como Agustín. Y de esta manera, a partir del siglo IV, la interpretación figural resultó de gran utilidad para la predicación y enseñanza de la nueva doctrina cristiana, convirtiéndose en una tradición consolidada en los sucesivos siglos, pues, para quien entendía el latín o alguna de las lenguas romances posteriores, el

http://www.vatican.va/archive/catechism_sp/p1s1c2a3_sp.html

35 De Genesi ad Litteram I, 1. «En todos los libros santos ha de preguntarse qué se relacione con las cosas eternas allí [sentido analógico-anagógico], qué hechos se narren [sentido histórico-literal], qué cosas futuras se anuncien [sentido interpretativo figural], qué preceptos se exhorte a cumplir [sentido moralalegórico]». Como se puede observar, tres de los cuatro significados adquieren un sentido históricamente concreto y uno moral-alegórico. Edición digital:

http://www.augustinus.it/latino/genesi_lettera/index2.htm

${ }^{36}$ De civitate Dei 20,14. «La figura de este mundo pasará, pero no quiero que penséis en ello. Es la figura y no la naturaleza, la que pasa».

${ }^{37}$ V. gr., De civitate Dei 10, 6; 15, 27; 16, 31 y 42; 17, 3, 4 y 6; 18, 11.

${ }^{38}$ Ver De catechizandis rudibus 3, 6-8. Edición digital:

http://www.augustinus.it/spagnolo/catechesi cristiana/index2.htm

39 Sermones 2, 6 ss.: «Ante todo, hermanos, os exhortamos y ordenamos en nombre del Señor, que cuando escuchéis exponer el misterio de las Escrituras que narra las cosas sucedidas, debéis creer que sucedieron tal cual os muestra lo leído; porque sin el fundamento de las cosas acaecidas construiríais en el vacío».

${ }^{40}$ De Spiritu et littera 14, 23: El cristiano debe comportarse «no según la ley de las obras, por la que nadie se justifica, sino según la ley de la fe, por la que vive el justo». 
término figura ya portaba la multiplicidad completa de las interpretaciones recogidas en el desarrollo histórico de su significado.

\section{La interpretación figural frente a otras formas figuradas de interpretación}

¿Es posible definir con rigor el significado de la interpretación figural? Para Auerbach la interpretación figural es “el modo de concebir figuralmente el acontecer histórico". Este modo interpretativo mediante la figura -la cual, como anteriormente vimos, para los Padres de la Iglesia implica una representación anticipada de algo- establece entre dos hechos o dos cosas, temporalmente separadas, una conexión en la que una de ellas, además de representarse a sí misma, significa y representa a la otra, mientras que la otra incluye a la primera y la consuma. Los dos elementos de la figura se sitúan en el tiempo como acontecimientos históricos universales, requiriendo para su comprensión de un acto espiritual, de una voluntad interpretativa que, considerando cada uno de los dos elementos o polos de la figura, se ocupe del material dado o esperado y del acontecer pasado, presente o futuro, pero no de conceptos o construcciones abstractas.

A partir de Agustín se tiende a representar con mayor profusión la contraposición entre los dos polos (figura y consumación) mediante tres etapas o fases graduales. Los dos elementos o polos de la figura representan algo provisional e incompleto que no se consumará definitivamente hasta el acontecer de la tercera fase, la cual sólo es una promesa integrada en la fase segunda. La relación entre los polos de la figura marca, por tanto, un futuro que supondrá el acontecimiento pleno y definitivo; y esta situación afecta tanto al AT como al NT. El proceso completo se puede resumir de la siguiente manera: primero, la ley o la historia de los judíos -contenida en el AT- como figura profética del primer advenimiento de Cristo; segundo, la Encarnación de Cristo contenida en el NT- como consumación de esta figura y, a la vez, como anuncio intemporal del segundo advenimiento de Cristo. Y por último la llegada futura de este acontecimiento en el fin de los tiempos, con el Juicio final y la venida del verdadero reino de Dios, como consumación definitiva de lo figurado en el AT como promesa de vida eterna ${ }^{41}$.

\footnotetext{
${ }^{41}$ Agustín, en Sermones 4, 9 indica lo siguiente: «El Antiguo Testamento es, pues, promesa figurada; el Nuevo Testamento es promesa espiritualmente entendida. Aunque la Jerusalén terrestre pertenece al
} 
De esta manera, indica Auerbach, a partir de la interpretación figural de Agustín la cual pasa a dominar la concepción de la realidad universal y terrenal en la Edad Media europea- las figuras no sólo son provisionales, sino que, al mismo tiempo, componen la configuración provisional de lo eterno y por tanto intemporal. En esta representación, la vida terrenal es del todo real, pues posee la realidad tangible en la que aconteció la palabra de Dios; pero esta realidad, a su vez, no es sino sombra y figura de lo auténtico y futuro, de la verdad definitiva del reino de Dios que, preservando la figura, contiene la realidad verdadera y eterna. Lo eterno está representado en las tres etapas o fases graduales de la interpretación figural y constituye una realidad tan inconclusa y provisional como velada y presente en todo momento. Así, el acontecer terrenal no se percibe como algo definitivo ni como una realidad autosuficiente, ni como un proceso generador de nuevos acontecimientos, sino que dicho acontecer se contempla ante todo como una conexión directa con un orden divino del que participa y respecto del cual también él será en el futuro una realidad acaecida y consumada. Es así como el acontecer terrenal de la profecía real o de la figura forma parte de la realidad que se consumará inmediata y perfectamente en el futuro. Pero esta realidad no es sólo futura, sino que a los ojos de Dios y en el más allá está eternamente presente, de tal forma que allí la realidad desvelada y verdadera existe desde siempre, intemporalmente.

Puesto que la interpretación figural pone una cosa en lugar de otra, haciendo que una signifique y represente a la otra, este modo interpretativo pertenece también a las distintas formas de representación alegóricas recogidas por Quintiliano ${ }^{42}$. Pero la interpretación figural -dice Auerbach- se distingue claramente de la mayor parte de las formas alegóricas que conocemos, dado que en ella se afronta la historicidad real tanto de la cosa significante como de la significada. En cambio, la mayor parte de las alegorías que

Antiguo Testamento, lleva la imagen de la Jerusalén celeste y pertenece al Nuevo». Edición digital: http://www.augustinus.it/spagnolo/discorsi/index2.htm

42 M. Fabio Quintiliano, Instituciones oratorias, tomo 2, libro VIII, cap. VI, 76: «La alegoría, que interpretamos inversión, muestra una cosa en las palabras y otra en el sentido, y también a veces lo contrario». La voz "alegoría", en el Tesoro de la lengua castellana (1611), de Sebastián de Covarrubias, dice: «Es una figura, cerca de los retóricos, cuando las palabras que decimos si[g]nifican una cosa y la intención con que las pronunciamos otra; y consta de muchas metáforas juntas...». El Diccionario de Autoridades (1726) se hace eco de la definición de Quintiliano, indicando que la alegoría es «un modo artificial de la oración, por el cual se esconde un sentido debajo de palabras que aparentemente dicen otra cosa: y continuándose unas y otras, así en el sentido, como en la intención, resulta este artificioso modo de hablar, que comúnmente está reputado por una de las figuras retóricas, o tropos. Es voz tomada del griego $\dot{\alpha} \lambda \lambda \eta \gamma \circ \varrho \dot{\omega} \omega$ [allegoria], de quien la recibió también el latino, y Quintiliano la llama Inversio». 
encontramos en la literatura y en las artes plásticas representan una virtud (v. gr., la sabiduría), una pasión (v. gr., la envidia), una institución (v. gr., el derecho) o, a lo sumo, una síntesis genérica de un fenómeno histórico (v. gr., la paz, la patria), pero nunca la plena historicidad de un hecho determinado. Y lo mismo sucede con las interpretaciones alegóricas tanto de acontecimientos históricos, legendarios o míticos, siendo indiferente la realidad de los mismos, puesto que lo habitual es que se interpreten como exposición velada de doctrinas filosóficas. Y de esta naturaleza es el método alegórico con el que tuvo que competir la interpretación figural en la exégesis bíblica, tal es el caso de Filón de Alejandría (I a.C.- I d.C.) ${ }^{43}$ y de la Escuela Catequética de Alejandría, influida por Filón, de la que el más significativo representante es el ya mencionado Orígenes.

Filón interpreta el AT en términos de filosofía griega, estableciendo de este modo un puente entre el judaísmo y el helenismo, y tomando cada uno de los acontecimientos del AT como las distintas fases del estado del alma y de su relación con el mundo inteligible. La Escuela de Alejandría recogió esta interpretación espiritual del AT para los textos y acontecimientos históricos y la hizo extensiva también para el mundo material inmediato, como las estrellas y los animales, despojando a todos de su realidad sensible e interpretándolos alegóricamente. El método alegórico de la Escuela Alejandrina se extendió junto con el figural a la Edad Media, y aunque ambos métodos son marcadamente distintos presentaban en común el hecho de la transformación del AT, ya que, en ambos métodos, la ley y la historia de Israel pierden su carácter nacional y popular, transformándose en el antecedente de la fe en J.C., que comporta un carácter universal. Pero, además, la interpretación alegórica-espiritual de la Escuela de Alejandría y sus sucesores desarrolla una doctrina moral, ética y mística que debilita profundamente el texto del AT, privándolo de su contenido histórico. Esta interpretación mantuvo su influyente posición durante largo tiempo, siendo determinante, como hemos visto, respecto de uno de los cuatro sentidos de la Escritura: el espiritual-alegórico. No obstante, por su origen y naturaleza, este método se restringió a un círculo pequeño de personas cultivadas e iniciadas. Por el contrario, el método figural de los Apóstoles y de gran parte de los Padres de la Iglesia consiguió extenderse y permanecer; y con la fuerza de la interpretación unitaria y teleológica de la historia universal y del orden providencial

\footnotetext{
${ }^{43}$ Ver método alegórico de Filón de Alejandría en Obras completas, tomo I, Edición digital: http://www.diostellama.com/pdf/26filondealejandriaobrascompletas.pdf
} 
del mundo que este método aporta, fue dando cuerpo a la teología de la emergente doctrina cristiana.

Además de las representaciones e interpretaciones alegóricas existen también otras formas de representar una cosa por medio de otra, que pueden compararse con la interpretación figural. Nos referimos a las formas simbólicas y míticas provenientes de las culturas primitivas. Lo característico de estas formas, indica Auerbach, consiste en que, para los participantes de ellas, lo significado es siempre algo sumamente importante, sagrado y determinante para su vida y pensamiento. En el signo o en el símbolo no sólo se expresa y se imita algo, sino que ese algo se considera presente y contenido en él: una actuación sobre el símbolo mismo repercute igualmente como una actuación sobre lo simbolizado. No obstante, las formas simbólicas presentan puntos comunes con la interpretación figural $-\mathrm{y}$, en algunos casos, con representación coincidente: v.gr., el sacramento de la Eucaristía-, pues también pretenden interpretar y organizar globalmente la vida, y ambas sólo son concebibles en el ámbito religioso o dominios semejantes. Mas las diferencias son manifiestas. De hecho, la figura se refiere siempre al acontecer histórico, el símbolo, no; la figura, en su origen, se dice de lo expresable mediante la palabra y de su significado e interpretación; el símbolo lleva en sí una interpretación inmediata de la vida, y en su origen sobre todo de la naturaleza.

Abundando en las representaciones alegóricas y simbólicas, Gershom Scholem ${ }^{44}$, el gran experto cabalista del s. XX, indica que la alegoría consiste en una red infinita de significados y correlaciones en la que todo puede convertirse en una representación de todo, pero siempre dentro de los límites del lenguaje y la expresión; y en este sentido se puede hablar de inmanencia alegórica. Lo que se expresa por medio de la alegoría es, en primer lugar, algo que tiene su propio contexto significativo, pero que, al transformarse en alegórico, pierde su propio significado y se convierte en vehículo de otra cosa. De esta manera, por ejemplo, la textura viva del relato religioso al convertirla en una alegoría queda destruida. La alegoría surge de la brecha que se abre en ese momento entre la forma y su significado. Ambos han dejado de estar indisolublemente unidos: el significado ya no se limita a esa forma particular, ni la forma a ese contenido significativo particular. En suma, lo que aparece en la alegoría es la infinidad de significados que acompañan a toda representación. Por el contrario, el símbolo es una forma de expresión

${ }^{44}$ Cfr. Gershom Scholem, Las grandes tendencias de la mística judía, Madrid, Siruela, 2006, 46-48. 
que trasciende radicalmente la esfera de la alegoría. En el símbolo místico, una realidad que para nosotros no está por sí sola dotada de forma ni de contorno se vuelve transparente y, de alguna manera, visible a través de otra realidad que recubre su contenido con un significado visible y expresable, v.gr., la cruz o el crismón para los cristianos. Si podemos definir la alegoría como la representación de algo expresable por medio de otra cosa expresable, el símbolo místico es la representación expresable de algo que se encuentra más allá de la esfera de la expresión y de la comunicación, algo que proviene de una esfera cuyo rostro está, por así decirlo, vuelto hacia dentro y alejado de nosotros: una realidad oculta e inexpresable encuentra su expresión en el símbolo. Allí donde una penetración más profunda en la estructura de la alegoría descubre nuevas posibilidades de significación, el símbolo se entiende inmediatamente por medio de la intuición o no se entiende en absoluto. De ahí la gran diferencia existente entre la interpretación alegórica de la religión que llevan a cabo los filósofos y su comprensión simbólica por parte de los místicos.

\section{Consideraciones acerca de la figura en los Pensées}

A partir del s. IV, con la extraordinaria expansión del cristianismo en el área septentrional de los países mediterráneos y en la Europa occidental y central, el AT se transformó a través de la interpretación figural: pasó de ser un libro de ley y una historia del pueblo de Israel a consistir en un conjunto de figuras de Cristo y de la redención. De esta manera el AT quedaba integrado en la nueva doctrina como elemento necesario de continuidad que diera razón de la unitaria visión del acontecer histórico y universal transmitido por la nueva religión. La historia nacional y el carácter propio del pueblo judío (un pueblo lejano y extraño) desaparecieron de la interpretación del AT, abriéndose la posibilidad de que este libro pudiera ser recibido por estos otros pueblos como algo más cercano a ellos, debido a la fuerza del nuevo mensaje universal en el que podían verse incluidos. Ciertamente -como indica Auerbach- ésta es una conclusión a la que se ha llegado con posterioridad, ajena al ámbito de pensamiento de los primeros apóstoles y Padres de la Iglesia que vivían entre paganos y judeocristianos ${ }^{45}$. Sin embargo, su relevancia es notoria en el desarrollo y consolidación de la nueva religión y simultáneamente del antijudaísmo

${ }^{45}$ Cfr. Günter Stemberger, El judaísmo clásico. Cultura e historia del período rabinico, 199-214. 
en la tradición cristiana, cuyas terribles consecuencias llegan hasta nuestros días. De esta manera, a los pueblos recién convertidos al cristianismo el AT llegó únicamente como profecía (principalmente real) o precedente de la vida, muerte y resurrección de J.C., con la exclusiva transmisión del acontecer histórico universal vinculado a la fe y doctrina cristianas. Y así, el AT, en su condición inicial de historia del pueblo judío y ley judía tardó mucho tiempo en introducirse en el ambiente desarrollado por el cristianismo europeo, y en cualquier caso no antes del siglo XVI con la Reforma protestante y su respuesta en la Contra-Reforma. Pocas décadas después, en pleno siglo del Barroco con sus disputas religiosas, Pascal comienza a desplegar su inacabada apología de la religión cristiana a la cual posteriormente se la denominó como Pensées. Si tomamos sus grandes líneas, magistralmente delineadas por Jean Mesnard ${ }^{46}$, y nos adentramos en la lectura de los fragmentos contenidos entre los legajos XII y XVIII (edición Lafuma), encontramos una sucesión de notas en las que Pascal muestra el camino mediante el cual se habilita (en el legajo XIX y ss.) para la exposición de los argumentos que sustenten la verdad de la religión cristiana mediante la interpretación de los complejos enunciados presentes en el AT y también de lo expresado en el NT. A partir del legajo XII su relato constata una evidencia: excepto para el auténtico creyente, la religión no resulta en absoluto clara: «si no os preocupáis más que de saber la verdad, eso es bastante para quedaros en paz. Pero si deseáis con todo vuestro corazón conocerla, no es suficiente: mirad los detalles» ${ }^{47}$. Mas para llevar a cabo este trabajo la razón presenta sus límites: no puede demostrar indudablemente la existencia de Dios, pues «no conocemos la existencia ni la naturaleza de Dios, porque no tiene ni extensión ni límite» ${ }^{48}$, pero tampoco puede demostrar con certeza que no exista. Y puesto que este ejercicio para el hombre es de imposible resultado satisfactorio, y la necesidad de elección es una constante en cada vida, Pascal realiza su apuesta ${ }^{49}$. Para él la religión cristiana recoge y valora los principios de la razón y,

\footnotetext{
${ }^{46}$ Jean Mesnard, Pascal. El hombre y su obra, Tecnos, Madrid, 1973, trad.: Pedro López Cortezo [original: Pascal, Hatier, Paris, 1967].

${ }^{47}$ Cfr. L 150, B 226.

48 Cfr. L 418, B 233.

${ }^{49} \mathrm{El}$ proceso argumentativo pascaliano lo sintetiza Mesnard en los siguientes términos: «puesto que la razón no puede determinar la elección, ¿qué nos aconseja nuestro interés? Apostemos por Dios: sacrifiquemos los bienes terrenales. Si Dios existe, ganamos los bienes celestes, infinitos en grandeza y duración. Si Dios no existe, perdemos los bienes terrenales, es decir, unos bienes finitos. Siendo iguales las probabilidades a favor y en contra de Dios, tenemos una probabilidad de ganar lo infinito y una probabilidad de perder lo finito. Aunque incluso tuviésemos una única probabilidad de ganar lo infinito y varias oportunidades de perder lo finito, la pérdida siempre será finita. La ganancia, por lo tanto, es
} 
a su vez, exige el control de sus excesos: si se excluye la razón, el hombre cae en el terreno de la superstición, pero si se admite únicamente la razón y no se controlan sus excesos el hombre se verá abocado al deísmo y a la incredulidad: «sumisión y uso de la razón, en lo que consiste el verdadero cristianismo» ${ }^{50}$. Sin embargo, aunque entre Dios y hombre la distancia es insalvable, sí que al hombre, mediante su entendimiento, le sería posible al menos proseguir en la búsqueda de la revelación de Dios si existiera un mediador entre Dios y hombre: «no conocemos a Dios sino por J.C. Sin este mediador queda suprimida toda comunicación con Dios [...] Todos los que han pretendido conocer a Dios y probarle sin J.C. no tenían sino pruebas incapaces [...] En Él y por Él conocemos, pues, a Dios» ${ }^{51}$. Y de esta manera Pascal se sitúa frente al AT como libro que contiene la promesa del mediador necesario entre Dios y hombre.

El legajo XIX, en el que Pascal expone su metodología interpretativa del AT mediante el uso de la figura, comienza y termina con dos contundentes afirmaciones que sintetizan la exposición del problema que recorre su lectura del viejo testamento: «Que la ley era figurativa» ${ }^{52}$; que «el viejo testamento es una cifra» ${ }^{53}$. La primera afirmación nos indica, en primer lugar, que el pensador francés es consciente de la potencialidad y diversidad de significados que la palabra figura abarca, tanto en la tradición pagana como en la cristiana; y de ahí su empleo único en sus notas frente a otras formas de representación de cosas, palabras o imágenes, como los símbolos o los tropos y sus tipos, los cuales presentan insuficientes -e incluso, a veces, equívocas- prestaciones para la adecuada interpretación de los complejos textos del AT. El ejemplo más notable se presenta con la alegoría, forma representativa con la cual la representación figural podría llegar a confundirse; mas la alegoría requiere de un proceso ficticio ${ }^{54}$ que Pascal en su exégesis figural rechaza. En segundo lugar, desde la posición de la fe cristiana, la ley judía "era", es decir, no está vigente, no se encuentra en observancia; lo cual concuerda, en este aspecto, con la interpretación figural paulina en relación con la contraposición entre

infinitamente superior a la pérdida: en presencia de lo infinito, lo finito tan solo es la nada. La razón nos manda, pues, apostar por Dios [...] Es preciso, pues, proseguir la búsqueda. ¿Habrá, por ello, que sacrificar la razón? No». Jean Mesnard, Pascal. El hombre y su obra, 152-153.

${ }^{50} \mathrm{~L} 167, \mathrm{~B} 269$.

${ }^{51}$ Cfr. L 189, B 547.

${ }^{52} \mathrm{~L} 245, \mathrm{~B} 647$.

${ }^{53}$ L 276, B 691.

${ }^{54}$ Ver lo anteriormente recogido en Quintiliano, Filón de Alejandría, Orígenes, Agustín y Gershom Scholem en relación con lo alegórico. 
ley y gracia, de manera que el carácter normativo del AT queda superado por la fe en J.C. Finalmente, con la afirmación que cierra el legajo XIX Pascal nos está indicando que el AT está cifrado, pues «cuando se sorprende una carta importante en la cual se halla un sentido claro, y en la que se dice, sin embargo, que su sentido está velado y oscurecido, que está oculto de tal modo que se vea esta carta sin verla y que se la entienda sin entenderla, ¿qué se debe pensar sino que es una cifra de doble sentido? Y tanto más cuanto que en ella se encuentran contrariedades manifiestas en el sentido literal» ${ }^{55}$. Por ello es necesario encontrar la «clave de la cifra» ${ }^{56}$ de doble sentido. Y así, con el indispensable análisis filológico de Erich Auerbach acerca de la figura como fondo de estudio, nos adentramos en la metodología figural pascaliana acotada principalmente entre las dos rotundas afirmaciones anteriormente significadas.

Pascal encuentra en la lectura de la Escritura pasajes claros, oscuros e incluso contrarios. Por ello, para nuestro autor la aceptación literal de los textos -cifrados, velados- no aporta la garantía necesaria como para reconocer la realidad histórica de los acontecimientos narrados en los mismos, de manera que es preciso encontrar un método seguro de interpretación, pues

para entender la Escritura, hay que tener un sentido en el cual todos los pasajes contrarios se armonicen; no basta tener uno que convenga a varios pasajes armónicos, sino tener uno que armonice los pasajes incluso contrarios. Todo autor tiene un sentido en el cual todos los pasajes contrarios se armonizan o bien no tiene sentido alguno. No se puede decir eso de la Escritura y de los profetas: con seguridad que tenían demasiado buen sentido. Es pues preciso buscar uno que armonice todas las contrariedades. El verdadero sentido no es el de los judíos, pero en J.C. todas las contradicciones son armonizadas [...] Si se toma la ley, los sacrificios y el reino por realidades, no se puede armonizar los pasajes; es pues necesariamente preciso que no sean más que figuras ${ }^{57}$.

Además, «para saber si la ley y los sacrificios son realidad o figura, hay que ver si los profetas, al hablar de tales cosas, detenían en ellas su visión y su pensamiento, de modo que no viesen allí más que esa antigua alianza [el AT como código de leyes e historia del

\footnotetext{
${ }^{55}$ Cfr. L 260, B 678.

${ }^{56} \mathrm{~L} 249, \mathrm{~B} 681$.

${ }^{57}$ Cfr. L 257, B 684.
} 
pueblo judío], o bien si veían alguna otra cosa de la cual ella fuera la pintura [imagen]. Pues en un retrato se ve la cosa figurada. No hay para ello más que examinar lo que de ella dicen: un retrato trae ausencia y presencia, placer y displacer. La realidad excluye ausencia y displacer» ${ }^{58}$; pero los profetas han «profetizando mediante figuras» ${ }^{59}$.

A lo cual hay que añadir que, para Pascal, las Escrituras no pueden admitirse ni como un libro divino ni como un libro simplemente humano, pues se cometerían dos enormes errores que anularían la verdad contenida en ellas: «1. Tomarlo todo literalmente. 2. Tomarlo todo espiritualmente ${ }^{60}$. De ahí que las tendencias hacia las interpretaciones extremas literales-reales o alegórico-espirituales confundan e introduzcan sombras en el desvelamiento de la verdad de estos acontecimientos más que ayudar a encontrar la clave de lo cifrado y expresado mediante figuras: hay que «hablar contra los demasiado grandes figurativos» ${ }^{61}$. Estas pautas expresan la misma inquietud y a su vez firmeza y certeza que lo concluido por Pablo en su segunda epístola a los Corintios: «hasta el día de hoy, sobre la lectura del AT sigue el mismo velo [figura] sin descorrerse, porque [sólo] en Cristo desaparece» ${ }^{62}$.

Por lo hasta aquí expuesto, es notorio que la exégesis figural pascaliana presenta notables diferencias en relación con la de los Padres de la Iglesia y sus tradicionales corrientes de interpretación figural del AT -representadas principalmente por Pablo, Tertuliano, Orígenes y Agustín-, las cuales fluctúan entre la profecía real y la representación alegórico-espiritual. Frente a estas interpretaciones, el significado de la palabra figura en Pascal únicamente es coincidente con estas corrientes tradicionales del cristianismo en cuanto a lo que la figura implica como representación de otro algo anunciado; pero diverge de ellas en cuanto al entendimiento literal de los textos del AT como profecía real -con la implícita pretensión de historicidad real tanto de lo figurado como de lo cumplido y consumado-, y también en lo que significa entender estos textos como representación alegórica-espiritual. Como el propio Pascal ha indicado, son los

\footnotetext{
${ }^{58}$ Cfr. L 260, B 678.

${ }^{59} \mathrm{~L} 248, \mathrm{~B} 653$.

${ }^{60} \mathrm{~L} 252, \mathrm{~B} 648$.

${ }^{61} \mathrm{~L} 254, \mathrm{~B} 649$.

${ }^{62}$ Cfr. II Corintios 3, 14.
} 
propios sabios los que profetizan ${ }^{63}$ de modo cifrado y velado (no imaginario o falso) mediante figuras. De esta manera, por un lado, el predicado "figurativo" que Pascal aplica a la ley, al AT, pone de manifiesto -como denuncia- la contraposición entre la imaginación y lo auténtico o verdadero, para lo cual el método analítico desarrollado en la búsqueda de lo velado o cifrado se apoyará en las enseñanzas de quienes pueden mostrar el camino hacia la única verdad posible. Por ello exclama Pascal: «¿Cuánto no deberemos, pues, estimar a quienes nos descubren la cifra y nos enseñan a conocer el sentido oculto, y principalmente cuando los principios a que se atienen son por completo naturales y claros? Es lo que J.C. hizo. Y los apóstoles. Abrieron el sello. Él rompió el velo y dejó al descubierto el espíritu. Ellos nos enseñaron mediante esto que los enemigos del hombre son sus pasiones, que el redentor sería espiritual y su reino espiritual, que habría dos advenimientos ${ }^{64}$, uno de miseria para rebajar al hombre soberbio, el otro de gloria para elevar al hombre humillado, que J.C. sería Dios y hombre» 65 . Por otro lado, y a su vez, lo "figurativo" en Pascal hace patente el hecho de la responsabilidad en la palabra que la mente debe interpretar, pues «las cosas de Dios, al ser inexpresables, no pueden ser dichas de otro modo [que de manera figurada], pues no está permitido atribuir a la Escritura sentidos que no nos ha revelado tener [...] Sino que decimos que el sentido literal no es el verdadero, porque los profetas mismos lo han dicho» ${ }^{66}$. La realidad, lo auténtico, la única verdad figurada sólo es posible desvelarla mediante su consumación; de ahí que, en la particular exégesis pascaliana, el AT sólo deba entenderse como un conjunto de libros que contienen narraciones figuradas, veladas, cifradas, y cuyo principal valor -ajeno a consideraciones de historicidad real de lo narrado en los textos o como código de leyes e historia del pueblo judío- es el de

${ }^{63}$ Cfr. L 295, B 629: 'Quis mibi det ut omnes prophetent'. Ver Números XI, 29: «[...] ¡Ojalá que todo el pueblo de Yahveh fuesen profetas, porque les infundiera su espíritu Yahveh!». F. Cantera-M. Iglesias, Sagrada Biblia, BAC, Madrid, 2003, 137.

${ }^{64}$ Hebreos 9, 27-28: «Y así como es el destino de los hombres morir una vez, y después de eso un juicio, así también Cristo, después que se ofreció una vez para cargar con [los] pecados de muchos, por segunda vez, sin [relación con el] pecado, se dejará ver de los que lo aguardan para salvarse». F. Cantera-M. Iglesias, Sagrada Biblia, 1388.

${ }^{65}$ Cfr. L 260, B 678.

${ }^{66}$ Cfr. L 272, B 687: «Aun cuando la palabra de Dios, que es verdadera, sea falsa literalmente, es verdadera espiritualmente. Sede a dextris meis (Salmo 110, 1-2: "Oráculo de Yahveh a mi señor: 'siéntate a mi derecha hasta que convierta a tus enemigos en escabel de tus pies'. El cetro de tu poderío extenderá Yahveh desde Sión: ¡domina en el corazón de tus enemigos!'”): esto es falso literalmente, es pues verdadero espiritualmente. En estas expresiones, se habla de Dios a la manera de los hombres. Y eso no significa otra cosa sino que la intención que los hombres tienen al hacer sentarse a Dios a su derecha, también Dios la tendrá. Es pues una marca de la intención de Dios, no de su manera de ejecutarla». 
servir de elemento necesario de transición hacia el NT, en el cual se cumple y consuma lo anunciado figuralmente en el AT. Y en este sentido puede entenderse la advertencia de Pascal a los contumaces en relación con la interpretación de los textos del AT, pues «un mismo sentido cambia según las palabras que lo expresen. Los sentidos reciben de las palabras su dignidad en lugar de conferírsela» ${ }^{67}$. $\mathrm{Y}$ así, «quien quiere dar el sentido de la Escritura y no lo toma de la Escritura es enemigo de la Escritura» ${ }^{68}$, esto es, contrario por efecto de sus pasiones- a la palabra que expresa la voluntad de Dios; y todo ello a pesar de que «J.C. les abrió el espíritu para entender las Escrituras» ${ }^{69}$, pues sólo por medio de J.C. se encuentra la clave que descifra. De esta manera, J.C. es el mediador buscado -único y necesario- entre Dios y hombre, al ser la realidad -la verdadconsumada de lo profetizado en el AT en clave de cifra. E incluso después de la muerte de J.C. «vino san Pablo a enseñar a los hombres que todas estas cosas habían sucedido en figura $^{70}$, que el reino de Dios no consistía en la carne sino en el espíritu, que los enemigos de los hombres no eran los babilonios, sino sus pasiones, que Dios no se complacía en los templos alzados por la mano, sino en un corazón puro y humillado, que la circuncisión del cuerpo era inútil, mas era necesaria la del corazón, que Moisés no les había dado el pan del cielo, etc. Mas, no habiendo Dios querido descubrir tales cosas a ese pueblo que era indigno de ellas y habiendo, no obstante, querido producirlas con el fin de que fuesen creídas, predijo su tiempo con claridad y las expresó algunas veces claramente, pero abundantemente en figuras, con el fin de que aquellos que aman las cosas figurantes se detuvieran allí y que aquellos que aman las figuradas las viesen allí» ${ }^{71}$, «pues la inteligencia de los bienes prometidos depende del corazón, que llama bien a lo que $\left.a m a^{72}\right\rangle^{73}$. Y así, «todo cuanto no va a la caridad es figura. El único objeto de la

\footnotetext{
${ }^{67} \mathrm{~L} 789, \mathrm{~B} 50$.

${ }^{68} \mathrm{~L} 251, \mathrm{~B} 900$.

${ }^{69}$ Cfr. L 253, B 679.

${ }^{70}$ I Corintios 10, 11 .

${ }^{71}$ Cfr. L 270, B 670.

72 Sintética frase de Pascal con la cual nos ofrece el mecanismo del afecto del deseo en el hombre. Su contemporáneo Baruch de Spinoza, en propuesta análoga, en su análisis sobre la naturaleza de los afectos indicaba que lo único que define al hombre es la cupiditas, y por ello «nosotros no intentamos, queremos, apetecemos ni deseamos algo porque lo juzguemos bueno, sino que, al contrario, juzgamos que algo es bueno porque lo intentamos, queremos, apetecemos y deseamos». Ética III, P9, Escolio.

${ }^{73}$ Cfr. L 255, B 758.
} 
Escritura es la caridad. Todo cuanto no va al único bien es figura suya. Ya que, puesto que no hay más que un objetivo, todo cuanto no va a él en palabras propias es figura ${ }^{74}$.

Además de establecer su método exegético figural sobre el AT, Pascal en estos fragmentos muestra la correlación entre el AT y el NT, coincidiendo en la finalidad con la tradición patrística, pero mostrando una vez más su alejamiento de las corrientes interpretativas profético reales y alegórico-espirituales. Y de esta forma cierra el círculo de la necesidad continuada y unificada de ambos libros como plataforma de la palabra que dé sentido y permita mostrar la verdad de la doctrina cristiana, ya que, «para probar de una vez ambos [Testamentos] no hay más que ver si las profecías de uno se cumplen en el otro. Para examinar las profecías hay que entenderlas. Pues, si se cree que no tienen más que un sentido, es seguro que el Mesías no habrá venido; pero, si tienen dos sentidos, es seguro que habrá venido en J.C.» ${ }^{75}$. En efecto, un único sentido en las Escrituras significaría entender los textos del AT en su sentido literal, quedándose únicamente con las cosas figurantes, aspecto sobre el cual ya ha mostrado Pascal, a través de lo comunicado por los profetas, su imposible admisión como verdadero. Por el contrario, para nuestro pensador son los dos sentidos de la Escritura (la cosa cifrada mediante la figuración en el AT, y lo descifrado a través de su consumación en el NT) lo que prueba la continuidad y unidad de ambos Testamentos. De esta manera, recogiendo lo teorizado en la antigua tradición cristiana como tercera fase de la interpretación figural (consumación definitiva de lo figurado en el AT como promesa de vida eterna), Blaise Pascal muestra también cómo el NT contiene necesariamente elementos figurales que implican una representación anticipada de otro algo: prenuncio del segundo advenimiento

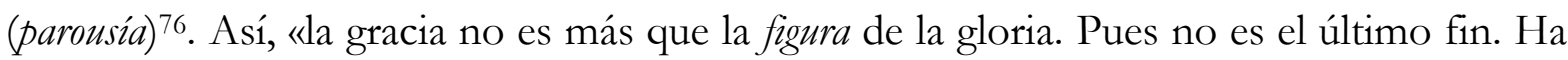
sido figurada por la ley y ella misma figura la gloria, pero es su figura y su principio o causa» $\rangle^{77}$; y, de esta manera, «la otra libertad ${ }^{78}$ no es más que una figura de la libertad $\left.{ }^{79}\right\rangle^{80}$ auténtica y verdadera de la gloria.

\footnotetext{
${ }^{74}$ Cfr. L 270, B 670.

75 Cfr. L 274, B 642.

76 Ver L 241, B 765; Hebreos 9, 27-28; Mateo 24, 36-42; Marcos 13, 32-35; Lucas 12, 35-40.

77 Cfr. L 275, B 643.

${ }^{78}$ La libertad carnal y efímera.

79 Juan 8, 34-36: «Jesús les respondió: "De verdad os aseguro: todo el que hace el pecado es esclavo del pecado; y el esclavo no se queda en la casa para siempre; el hijo se queda para siempre. Así que, si el Hijo os hace libres seréis realmente libres"». F. Cantera-M. Iglesias, Sagrada Biblia, 1214.

${ }^{80}$ Cfr. L 268, B 683.
} 